\title{
O LIVRO E O TEMPLO: POESIA FLAVIANA E ARTE COTIDIANA
}

\author{
LENI RIBEIRO LEITE* \\ Universidade Federal do Espírito Santo
}

Resumo. A partir da compreensão de que a écfrase é um elemento retórico cujos limites eram mais amplos no mundo antigo do que em nossa contemporaneidade, este artigo tem por objetivo discutir a função da écfrase de objetos cotidianos nas poéticas de Marcial e Estácio como indicativos de mudanças sociais e culturais do período flaviano. Palavras-chave. Estácio; Marcial; écfrase; poesia flaviana; literatura imperial romana. D.O.I. 10.11606/issn.2358-3150.v18i1p85-93

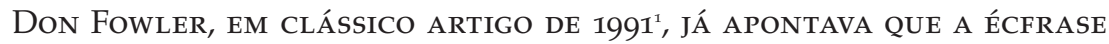
era então tema de grande interesse por parte de pesquisadoras de várias áreas, e em especial da área de Estudos Clássicos, no século xx. Tal interesse se manteve vivo na primeira década do século XxI, e não há indícios de um declínio, conforme atestam os vários textos sobre o assunto publicados em revistas acadêmicas a partir de 2009. Fowler, em seu artigo, trata especificamente - e chama atenção para isso logo nas primeiras frases - da écfrase da obra de arte. Como bem sabia Fowler, no entanto, ékphrasis no mundo antigo e no mundo moderno não são a mesma coisa, e a definição de écfrase como descrição de uma obra de arte visual é bastante recente.

No mundo antigo, as definições que temos de ékphrasis nos progymnasmata não se referem nem mesmo a obras de arte, como também não o faz Quintiliano. Ruth Webb e James Francis, entre outros, escreveram satisfatoriamente sobre este tema. Francis cita, a título de exemplo, mas como representativa da definição de ékphrasis no mundo antigo, a de Téon: "Ékphrasis é linguagem descritiva, trazendo o que é retratado claramente diante dos olhos. Há ékphrasis de pessoas e eventos e lugares e períodos de tempo."³.

* Doutora em Letras (Letras Clássicas) pela Universidade Federal do Rio de Janeiro (2008). Professora Adjunta II da Universidade Federal do Espírito Santo.

** Artigo recebido em 05.ago.2015 e aceito para publicação em 31.out.2015.

${ }^{1}$ Fowler 1991.

${ }^{2}$ Webb 2009.

${ }^{3}$ Francis 2009, 4. 
Segundo Webb, o termo ékphrasis desenvolveu-se tardiamente e definia, na antiguidade, apenas uma descrição evocativa, que punha o objeto diante dos olho - sub oculos subiectio, como diz Quintiliano.

O próprio Quintiliano fala mais especificamente de descrições ficcionais de eventos ou situações: "Consequemur autem, ut manifesta sint, si fuerint verisimilia; et licebit etiam falso adfingere quidquid fieri solet" ("Obteremos, porém, se forem verossímeis, que sejam claros; e será permitido também inventar elementos falsos, quando costumam ocorrer"). ${ }^{4} \mathrm{e}$ "Nec solum quae facta sint aut fiant sed etiam quae futura sint aut futura fuerint imaginamur. Mire tractat hoc Cicero pro Milone, quae facturus fuerit Clodius si praeturam invasisset" ("Não representamos só o que aconteceu ou está acontecendo, mas também o que poderá ou poderia acontecer. Cícero o fez admiravelmente no Pro Milone, quando descreveu o que Clódio teria feito se tivesse se tornado pretor"). ${ }^{5}$

Uma vez que se admita que a definição de écfrase na Antiguidade parece mais ampla do que a definição de écfrase mais comum na modernidade, parece claro, que o uso da écfrase poderia ser igualmente mais amplo naquele momento. Por um lado, havia a possibilidade de uma maior variedade no tema: em obras do mundo antigo, pode-se reconhecer écfrase em descrições que não se referem a obras de arte, mas também a casas, templos, uillae, banhos - a arquitetura em geral - e altares, mesas, candelabros, jarros para água, livros - a objetos do cotidiano. Por outro lado, a écfrase não estava presa a um gênero ou uma forma literários: é um expediente retórico que se faz presente em todo lugar.

A compreensão corrente acerca desta exclusividade da écfrase em relação a certo tipo de texto - em especial o texto de cunho narrativo, como a épica - é exemplificada pela estranheza criada, pelo menos em alguns meios, pelo conceito de "epigrama ecfrástico", um termo que surgiu em meio ao interesse renovado sobre o epigrama helenístico, em geral, e o epigrama sobre obras de arte, em especial. Em geral critica-se o uso do termo "epigrama ecfrástico" argumentando que os epigramas, por sua própria parca extensão, não poderiam dar uma descrição vívida de qualquer coisa, e que os epigramas normalmente denominados ecfrásticos são meramente epigramas a respeito de estátuas, pinturas, gemas e outros objetos de cunho artístico. Esta categoria de "epigrama ecfrástico" é discutida por Michael Squire ${ }^{6}$ e já o fora antes por Jas Elsner, para quem "Os escritores e leitores gregos e romanos reconheceriam a descrição da obra de arte como um exemplo paradig-

${ }^{4}$ Quint. Inst. 8.3.70.

${ }^{5}$ Quint. Inst. 9.2.41.

${ }^{6}$ Squire 2009 e 2010.

Let. Cláss., São Paulo, v.18, n. 1, p. 85-93, 2014 
mático de écfrase, com um significado próximo do uso moderno."” Squire, em contrapartida, argumenta que o problema aqui está na própria definição de écfrase como uma passagem textual que necessariamente evoca aspectos formais e físicos do objeto descrito - isto é, a incompatibilidade entre epigrama e écfrase só pode ser justificada em função daquela diferença de compreensão do que seja a écfrase que já mencionamos antes.

A partir da discussão de Webb (2009), percebe-se que essa definição moderna tende a considerar a écfrase dentro de uma definição simplista de enargeia. A nossa discussão aqui parte do entendimento que os autores da Antiguidade, inclusive os que se dedicaram aos gêneros de menor extensão e de ocasião, como Marcial na totalidade de sua obra e Estácio nas Siluae, estariam imersos em um diálogo bem mais sofisticado acerca do que se vê e do que se lê, entre a representação textual do visual, do que o que se entrevê na definição moderna de écfrase e, portanto, estariam prontos a inserir-se neste diálogo, mesmo a partir dos espaços diminutos e humiliores de suas poéticas.

Michael Squire (2010) faz reflexões acerca do epigrama ecfrástico a partir da série de poemas sobre a vaca de Míron, contidas em sua maioria na Antologia Palatina. Algumas das observações que Squire faz em relação ao epigrama grego valem também para o epigrama de Marcial, como procuraremos demonstrar.

Squire analisa, em relação aos epigramas sobre a vaca de Míron, por um lado, a retórica do realismo da obra de arte; por outro, o significado daquela retórica dentro do epigrama enquanto entidade antologizada e antologizável. A vaca de Míron surgiria então como um ícone da própria simulação poética da poesia epigramática. A estátua ou obra de arte é uma mímese da vida - de fato, em grande parte dos epigramas, a característica mais importante da obra de arte é a sua perfeição que a faz quase viva. Assim como a vaca de Míron, vários epigramas de Marcial sobre obras de arte sublinham a verissimilitude da obra, a aparência de real.

Artis Phidiacae toreuma clarum

pisces aspicis: adde aquam, natabunt. ${ }^{8}$

Tu vês os peixes, famoso afresco, arte de Fídias.

Dê-lhes água, nadarão.

A imagem se refere ao modelo que está ausente, da mesma forma como a écfrase se refere a uma imagem ausente. Mas, assim como acontece com o afresco, a écfrase faz o que era ausente, presente, comunicando, através das 
palavras, a imagem; apropriando-se de matéria visual e fazendo-a verbal, a écfrase transforma os leitores em espectadores. Em suma, a écfrase é uma interface dinâmica entre visual e verbal.

A poesia epigramática apresenta-se muitas vezes ela mesma também como uma réplica quase perfeita, mas não apenas de um objeto, e sim da vida.

Scribant ista graues nimium nimiumque seueri,
quos media miseros nocte lucerna uidet;
at tu Romano lepidos sale tinge libellos:
adgnoscat mores uita legatque suos. ${ }^{9}$

Que os muito severos escrevam estas coisas muito graves, Infelizes que o lampião observa à meia-noite.

Quanto a ti, mergulha os lépidos livros no sal romano:

que a vida leia e reconheça neles seus costumes.

Qui legis Oedipoden caligantemque Thyesten,

Colchidas et Scyllas, quid nisi monstra legis?

Quid tibi raptus Hylas, quid Parthenopaeus et Attis,

Quid tibi dormitor proderit Endymion?

Exutusve puer pinnis labentibus? aut qui

Odit amatrices Hermaphroditus aquas?

Quid te vana iuvant miserae ludibria chartae?

Hoc lege, quod possit dicere vita 'Meum est..'10

Tu que lês o Édipo e o sombrio Tiestes, e as mulheres da

Cólquida e as Cilas, o que lês a não ser monstruosidades?

O que tens tu com o rapto de Hilas, com Partenopeu e Átis,

de que te adianta o sonolento Endímio?

Ou o menino despido das asas perdidas?

Ou Hermafrodito que odeia as águas amorosas?

De que te servem as mentiras vãs de um papel miserável?

Lê isto aqui, que a vida pode chamar de seu.

A obra de arte é portanto réplica; o epigrama é igualmente réplica da vida. Seria então o epigrama que trata da réplica, em si, uma réplica da réplica que, no fim das contas, perpetua a obra? Squire sugere que este jogo de espelhos do epigrama sobre a imagem mimética em si é uma representação do próprio status do epigrama enquanto simulação poética. A realidade virtual dos peixes, das vacas, das estátuas é um ícone metapoético para a virtualidade do próprio epigrama; a credibilidade da obra de arte é uma metáfora para a credibilidade do epigrama. Ele mesmo destacado da base da estátua ou da pedra da lápide, o epigrama mantém a deixis original

\footnotetext{
${ }^{9}$ Mart. 8.3.17-20.

${ }^{10}$ Mart. 10.4.1-8.
}

Let. Cláss., São Paulo, v. 18, n. 1, p. 85-93, 2014 
das inscrições, mas simplesmente não há mais materialidade que suporte o demonstrativo.

Ingenium mihi, Gaure, probas sic esse pusillum, carmina quod faciam quae brevitate placent.

Confiteor. Sed tu bis senis grandia libris

qui scribis Priami proelia, magnus homo es?

Nos facimus Bruti puerum, nos Langona vivum:

tu magnus luteum, Gaure, Giganta facis. ${ }^{11}$

Provas assim, Gauro, que meu engenho é modesto:

porque eu faço poemas que agradam pela brevidade.

Eu confesso. Mas tu, que escreves duas vezes meia dúzia de livros

Sobre as grandes batalhas de Príamo, é um grande homem?

Nós criamos um menino de Bruto ${ }^{12}$ vivo, um Lagon ${ }^{13}$ vivo:

$\mathrm{Tu}$, Gauro, grande homem, fazes um gigante de barro.

Os epigramas de Marcial são, então, como as estátuas de Fídias, de Míron, de Licisco: eles oferecem algo muito semelhante ao mundo. A própria linguagem da écfrase é a linguagem do símile, como apontam Fowler e Francis: "Os símiles chamam a atenção simultaneamente para a vivacidade e vigor da representação, e para o fato de que aquilo é uma representação, e não a 'coisa real'." ${ }^{14}$ No entanto, em um contexto romano imperial, o arranjo universal das coisas e a ordem correta do mundo já não é mais representada pelos costumes tradicionais, pelo Zeus Olímpico de Fídias, e sim por Roma e seu império.

A percepção de uma alteração estética e moral ocorrida nos primeiros séculos do império romano não é uma novidade. O período dos imperadores flavianos, a ascensão de uma dinastia que não podia reclamar para si a legitimação dos júlio-cláudios, pode ser apontado como aquele em que as mudanças, desenvolvendo-se a partir da morte de Augusto, alcançam um novo patamar, e as obras de Plínio, o Velho, Plínio, o Jovem e Estácio têm sido usadas com frequência no estabelecimento dessas alterações.

As Siluae, de Estácio, são uma coleção de poemas de curta e média extensão, escritos como poesia de ocasião, que frequentemente exemplificam o

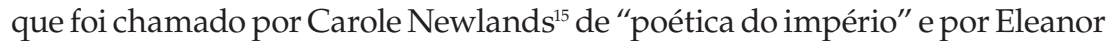
Leach ${ }^{16}$ de "cultura do elogio". Tanto as Siluae de Estácio como os Epigrammata

\footnotetext{
${ }^{11}$ Mart. 9.50.

${ }^{12}$ Estatueta de um menino, pertencente a M. Bruto. Cf. Plin. Nat. 34.82.

${ }^{13}$ Estatueta de um menino, feita por Licisco. Cf. Plin., Nat. 34.79.

${ }^{14}$ Francis 2009, 14.

${ }^{15}$ Newlands 2002.

${ }^{16}$ Leach 2003.
} 
de Marcial apresentam como personagens indivíduos de diferentes estratos sociais, do imperador aos libertos; nas duas obras, misturam-se os espaços privados e públicos, e as referências ao luxo e riqueza, das uillae aristocráticas ao palácio imperial, chamam a atenção pela atitude. Afastando Catão, exemplo máximo de moralidade e moderação, Marcial marca uma mudança na ideia do luxo, visto como algo bom, desejável e indicador de riqueza interior - ao invés de marca de decadência e desmoralização da sociedade.

McNelis, em artigo de 2008, analisa dois epigramas de Marcial, 9.43 e 9.44, e um poema de Estácio, Siluae 4.6, que tratam de um tema comum - o de uma obra de arte, a estátua do Hércules Epitrapézios pertencente a Novio Vindex. McNelis dá ênfase mais às diferenças do que às semelhanças no tratamento dado por Marcial e Estácio à estátua de Hércules, mas enfatiza que, em ambos os casos, há a mudança do público para o privado: "Assim como o poema de Estácio, o epigrama de Marcial cita a impressionante lista de antigos possuidores [da estátua] e indica uma bem-vinda mudança de um contexto público - ou mesmo autocrático - para um privado."17. Além disso, essa mesma linhagem de donos por que a pequena estátua de Hércules passa - de Alexandre para Aníbal, de Aníbal para Sila, de Sila para Vindex - é, tanto em Estácio como em Marcial uma passagem da guerra para a paz, dos grandes generais para um campeão das artes e da literatura, dos ódios e do derramamento de sangue para a amizade entre os homens. Esse pensamento é igualmente representativo da homogenia do poder de Roma, de um novo estado de coisas estabelecido pelo império, em que é possível viver a paz e os seus benefícios graças ao imperador. A obra de arte, bem como sua descrição na literatura, se prestam assim a representar este novo modo, no âmbito social e literário.

A écfrase, no período flaviano, se volta com frequência para elementos do cotidiano. Já em 1976 Carmelo Salemme publicara Marziale e la poetica degli oggetti, observando o papel dos objetos como parte importante da poética do autor, não só nos livros de dedicatórias, Xenia e Apophoreta, mas em todos os demais. Talvez seja apenas que, devido ao afluxo de bens materiais e de riqueza para a cidade Roma, a partir de todos os cantos das províncias, tenham sido elevados à categoria de arte os objetos do cotidiano. Fato é, porém, que os elementos arquitetônicos - as casas, os templos, as uillae, os banhos - e os objetos em si - os copos, utensílios domésticos variados, e mesmo o livro - são dignos de descrições vivazes e eloquentes, que os ponham diante dos olhos.

\footnotetext{
${ }^{17}$ McNelis 2008, 268.
} 
O poema 5 do primeiro livro das Siluae é uma descrição dos banhos construídos na propriedade de Cláudio Etrusco. Nos primeiros versos, o poeta informa que o poema é apenas um descanso de seu trabalho sério, ou seja, da composição da Tebaida:

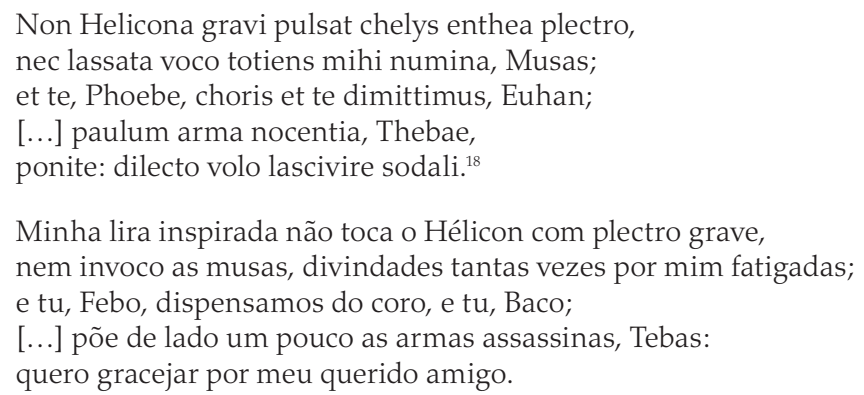

Mais adiante, a descrição da seleção de mármores coloridos decorando os banhos elegantes de Cláudio Etrusco, o próspero filho de um liberto imperial, não admite nada da pobreza (nil plebium est), transforma o espaço privado em um bosque das Musas (non unquam aliis habitastis in antris / ditius) e não perde na comparação com o salão de banquetes de Domiciano, objeto de descrição no poema 4.2. Neste, cinco diferentes tipos de mármore são nomeados, e mais de cem colunas competem com Atlas na habilidade de carregar tamanho peso sobre os ombros. Frequentemente os mármores, as jóias e outros objetos de luxo são nomeados através de referências a sua origem: numídio, frígio, egípcio, mostrando que as suas descrições são direcionadas a um público culto.

Carole Newlands afirma que: "obras de arte ou de arquitetura são sinais complexos que expressam mitos sociais e políticos poderosos em linguagem visual. A écfrase, portanto, oferece uma estratégia significativa para o poeta do elogio, pois a exploração de um signo complexo pode convidar à interpretação e interrogação de sua mitologia subjacente". ${ }^{19}$ Sabemos que tanto Estácio como Marcial foram vítimas de um descaso quase completo nos séculos XIX e xx justamente por causa da já referida "cultura do elogio", pelo muito de laudatório e encomiástico que há na poesia desses autores, um traço profundamente antitético em relação ao gosto moderno. A écfrase em Estácio e, acreditamos, também em Marcial, é parte da construção dessa poética imperial que precisa transmitir os sinais da nova cultura

\footnotetext{
${ }^{18}$ Stat. Silv. 1.5.1-3,8-9.

${ }_{19}$ Newlands 2002, 39.
} 
imperial e, por isso, está profundamente ligada ao aspecto encomiástico da obra de ambos os autores.

Os banhos de Cláudio Etrusco com seus mármores retirados das pedreiras imperiais são um sinal do poder e opulência de Roma, tanto quanto a estátua equestre de Domiciano, tema do primeiro poema das Siluae, em si uma extensa écfrase. Ao descrever uma mesa de pés de marfim, Marcial também se insere no espírito laudatório da época, também o aproxima dos amici maiores, dentre os quais o mais importante seja talvez o imperador. Ao descrever que o livro que segue para a residência do imperador e chega às mãos de seu secretário é coberto de púrpura e bem polido pela pedra, Marcial está transformando as palavras em um objeto cotidiano revestido da grandeza de uma coluna de mármore e da elegância dos assentos estofados que mobiliavam o templo de Hércules, tema do poema 3.1 de Estácio.

Todas essas obras de arte, esses elementos arquitetônicos, esses objetos de luxo têm, além de sua função dentro dos limites do próprio construto poético, uma face encomiástica, uma face que interpreta uma atitude cultural. Afinal, mais do que nos dizer da aparência de um objeto, a écfrase nos fala de como aquele objeto é percebido naquela sociedade. Os objetos descritos por Estácio e por Marcial são formas culturais que expressam visualmente uma linguagem de poder, de autoridade, de riqueza, de otium. A écfrase, enquanto expediente retórico e poético, vem auxiliar o estabelecimento, no período flaviano, de uma nova poesia cotidiana que dialoga diretamente com as mudanças culturais e políticas do período.

\section{REFERÊNCIAS}

Elsner, J. 2002. "Introduction: The Genres of Ékphrasis." Ramus 31:1-18.

Fowler, D. P. 1991. "Narrate and Describe: The Problem of Ékphrasis." The Journal of Roman Studies 81:25-35.

Francis, J. A. 2009. "Metal Maidens, Achilles' Shield, and Pandora: The Beginnings of Ékphrasis." American Journal of Philology 130(1):1-23.

Leach, E. W. 2003. "Otium as Luxuria: economy of status in the Younger Pliny's Letters." Arethusa 36(2):147-65.

McNelis, C. 2008. "Ut Sculptura Poesis: Statius, Martial, and the Hercules Epitrapezios of Novius Vindex." American Journal of Philology 129(2):255-76.

Newlands, C. 2002. Statius' Silvae and the Poetics of Empire. Cambridge: Cambridge University Press, 2002.

Squire, M. 2009. Image and Text in Graeco-Roman Antiquity. Cambridge: Cambridge University Press. 
Squire, M. 2010. "Making Myron's Cow Moo? Ecphrastic Epigram and the Poetics of Simulation." American Journal of Philology 131(4):589-634.

Webb, R. 2009. Ékphrasis, Imagination and Persuasion in Ancient Rhetorical Theory and Practice. Farnham: Ashgate Publishing.

\section{$*$}

Title. The book and the temple: Flavian poetry and everyday art

Abstract. Understanding that ekphrasis as a rethorical device was employed in Ancient times in much broader terms than in our contemporary world, this paper aims at discussing the role of ekphrasis of daily objects in the poetry of Martial and Statius as a sign of social and cultural changes that took place under Flavian rule.

Keywords. Statius; Martial; ekphrasis in Latin literature; Flavian poetry; Roman Imperial literature. 